\title{
BERYLLIUM DISEASE
}

\author{
By I. B. Sneddon, M.B., Ch.B., F.R.C.P. \\ Consultant Dermatologist, Rupert Hallam Department of Dermatology, Sheffield
}

It is opportune in a symposium on sarcoidosis to discuss beryllium disease because it mimics so closely the naturally occurring Boecks sarcoid and yet carries a far graver prognosis.

Beryllium was first reported to possess toxic properties by Weber and Englehardt (1933) in Germany. They described bronchitis and acute respiratory disease in workers extracting beryllium from ore. Similar observations were made by Marradi Fabroni (1935) in Italy and Gelman (1936) in Russia. Further reports came from Germany in 1942 where beryllium poisoning was recognized as a compensatable disease. Towards the end of World War II the production and use of beryllium salts increased greatly in the United States, and in 1943 Van Ordstrand et al. reported the first examples of chemical pneumonia in men extracting beryllium oxide from ore in Ohio. In addition to the acute respiratory disease, it had also been recognized that an acute contact dermatitis and ulcers resembling chrome ulcers occurred amongst workers in beryllium extraction plants, but it was not until 1946 that the first examples of delayed chemical pneumonitis were described by Hardy and Tabershaw.

They drew attention to a slowly progressive sarcoid-like change which involved the lungs, liver and other organs in workers who had been exposed sometimes for a very short time to beryllium compounds. The striking feature of the condition was the long latent period between exposure to beryllium and the onset of symptoms. This delay at first lead to doubt that beryllium itself was responsible for the pathological changes and even as recently as $195 \mathrm{I}$ an annotation in the Lancet suggested that the case against beryllium was not proven, though this was later contradicted by Harriet Hardy (195I) who has so vigorously campaigned for better recognition of the danger. It is in deference to her that the condition is called beryllium disease in this article.

Since that time more and more cases have been described in the United States of America. In 1953 Denardi et al., in an authoritative review of the subject, reported 35 examples of chronic pul- monary berylliosis which fulfilled the most stringent diagnostic criteria.

A beryllium case registry set up at the Massachusetts General Hospital by Dr. Harriet Hardy had collected by 1956309 examples of the disease, of whom 84 had died. The constant finding of beryllium in autopsy material from the fatal cases had proved beyond doubt the association between the granulomatous reaction and the metal.

It is difficult to reconcile the paucity of accounts of beryllium disease in this country with the large amount of beryllium compounds which have been used in the last ten years. The only reports in the medical literature are those of Agate (1948), Sneddon (1955), and Rogers (1957), but severa others have reached public notice in the dails press by reports of coroners' inquests and medicose legal actions. It is possible that there are others undiagnosed which are at present labelled Boeck's sarcoidosis.

\section{Pathology}

The basic pathological change seen in material from three autopsies by Chesner (1950) was an intra-alveolar nodular granulomatous lesion which involved all the lung fields. The nodules were composed of a preponderance of large endothelial cells with plasma cells, mononuclears and lymphocytes. There was no caseation at any stage. Giant cells of both foreign body and Langhan's type were seen in large numbers. Inclusion bodies were seen within the giant cells in some but not all cases. Spread occurred by aggregation of nodules in a more diffuse fashion throughout the alveolar septa. The diffuse reaction was at first a polymorphous cellular one with later fibrosis and hyalinization.

Hilar lymph nodes were invariably affected by the same granulomatous process. The liver was involved in two of the three cases, but there were no other visceral lesions. Similar granulomatous reactions have been described in skin lesions associated with beryllium disease of the lung by Grier et al. (1948), who also gave the first account 
of skin nodules due to accidental implantation of beryllium in the skin.

Lederer and Savage (1954), who have described the only example of beryllium granuloma of the skin in this country, noted pathological changes indistinguishable from sarcoidosis in part of the lesion but extensive caseation in other areas.

Although most investigators have failed to produce pulmonary granulomata in animal experiments with beryllium compounds, Davies and Harding (1950) succeeded in causing pulmonary granulomata in rats after intra-tracheal injection of a mixture of beryllium oxide and manganese dioxide.

\section{Clinical Features}

Symptoms may arise after a latent period from the last exposure to beryllium, of a few months to over ten years, and the exposure time need only be a few weeks. Although the majority of patients have worked in contact with beryllium compounds, Sterne and Eisenbud (195I) have recorded beryllium disease in residents in the near neighbourhood of beryllium extraction plants where the air contained less than r $\mu$ g. of beryllium per million parts and was probably as low as o.r $\mu \mathrm{g}$. per million. The disease has also affected relatives of beryllium workers whose only contact was with soiled working clothes.

The onset is insidious with dyspnoea on exertion, one of the first complaints. A dry paroxysmal cough, fatigue and loss of weight associated with anorexia are usual and periods of fever may occur.

As in sarcoidosis, quite advanced changes may be present in the lungs without symptoms, and such cases are discovered on routine chest radiography.

Physical signs are usually minimal though clubbing of the fingers and crackling rales throughout both lung fields and pleural friction have been described. Enlargement of the liver and spleen may be found, but enlarged superficial lymph glands are very rare. Skin nodules of the same type as those seen in sarcoidosis have occurred occasionally, and in the author's case linear sarcoid infiltrations in the site of previous skin damage by beryllium copper strip were a presenting and unusual feature.

\section{Investigative Procedure}

As Hardy (1956) has pointed out, many of the laboratory procedures such as total serum proteins and globulin, electrophoretic pattern of serum, liver function studies, urinary and serum calcium and urinary steroids may show abnormalities in beryllium disease just as they may in sarcoidosis, and therefore they are of little or no assistance when attempting to differentiate the two conditions.

Equally, respiratory function studies which show diminished vital capacity and slowing of alveolar diffusion in beryllium disease are merely a measurement of the severity of the lung damage. Impairment of respiratory function is, however, found earlier and is more severe in beryllium disease than in sarcoidosis.

Wilson (1948) has described the radiographic appearance of the lungs as being in three stages:

(I) A fine ground-glass granularity through the whole of the lung fields;

(2) A superimposed recticular pattern; and

(3) Very characteristic nodulation. The nodules varying in size from small to quite large, but not all cases progress through these stages.

Hilar gland enlargement does occur but never without densities in the lung fields. It is noteworthy that the early changes may be so finely granular that miniature mass radiography may not show them.

Many of the American articles do not refer to the results of tuberculin skin tests, but Hardy states that in her series of cases, in contrast to sarcoidosis, the responses have not differed from those of the general population. On the other hand, Agate's patient showed a change from a positive Mantoux reaction of $1 / 1,000$ to negative during the course of the illness, and in Rogers' (1957) patient and in two of the author's cases the Mantoux test was negative.

The Kveim test has only been performed on a few patients with beryllium disease, and the results have either been negative or a non-specific foreign body reaction.

Biopsy of the liver may reveal a sarcoid-like granulomatous reaction indistinguishable from sarcoidosis.

\section{The Differential Diagnosis}

The differential diagnosis of beryllium disease includes miliary tuberculosis, miliary carcinomatosis, pneumoconiosis and haemosiderosis, but above all else it resembles Boeck's sarcoidosis and the majority of reported cases were first thought to be that condition.

There are some differences between the two. For instance, no lesions of the eye, parotid or tonsil have been found in beryllium disease, and cervical and axillary node enlargement is rare. No cystic bone changes have ever been reported. The course of beryllium disease tends to be more rapidly downhill than that of sarcoidosis, but these slight differences are not of sufficient importance to tip the scale when faced with a patient.

The original criteria of diagnosis of beryllium disease established by American workers were: 
(I) History of exposure to dusts and fumes of beryllium compounds.

(2) Clinical course of the pulmonary syndrome including studies of pulmonary function.

(3) Radiographic evidence of granuloma of the lung.

(4) Lung biopsy and analysis for beryllium.

In 1953, Denardi et al. reported the reliability of skin patch tests carried out with dilute solutions of beryllium salts in distinguishing between beryllium disease and other conditions which simulate it.

They obtained an eczematous reaction beneath the patch tests in 12 cases and a negative response in five other patients with various lung diseases including sarcoidosis.

Van Ordstrand (I954) confirmed the reliability of this method and stated that so far he had no knowledge of a false positive result.

In the patient I described in 1955 markedly intense eczematous reactions were obtained by patch tests with I per cent. and 2 per cent. solutions of beryllium sulphate and nitrate. Usually in epidermal hypersensitivity, positive eczematous patch test reactions subside within a few days, but in this patient an inflammatory reaction was present three weeks later. The skin still showed erythema, scaling, and perceptible infiltration; a biopsy from the inflamed area revealed pronounced pseudo-tuberculous reaction in the dermis, but insignificant epidermal changes.

In order to confirm that this was a specific test, similar patch tests were carried out on over 100 normal controls and all were negative. Negative tests were obtained on 30 patients suffering from sarcoidosis (Geraint James, 1956).

Since that time I have repeated the test on a second case of beryllium disease, and I have knowledge of a third positive patch test which remained visible for some weeks but in which no biopsy was performed (Jordan, I957).

This modification of the original patch test appears to be a valuable diagnostic method though it must be admitted that there is a risk of activating the disease by introducing fresh beryllium into the patient.

The importance of obtaining an accurate diagnosis would appear to justify this slight risk, and it is a simpler and even safer method of confirming the diagnosis than lung biopsy.

It should be understood that patch tests should not be used on any patient who is likely to come in contact with beryllium again because Curtis (I95 I) has shown that it is only too easy to sensitize normal individuals. Eight out of 16 of his control subjects develops eczematous reactions one to two weeks later. It would be doubly

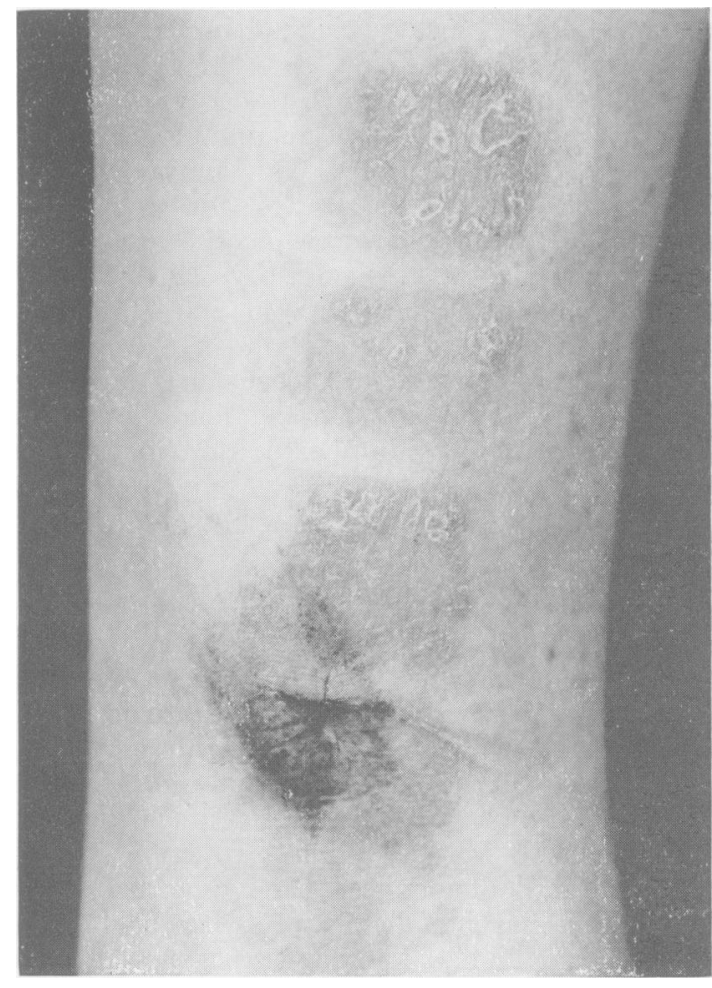

FIG. I.-Positive patch test to beryllium salts after three weeks showing infiltration and scaling.

hazardous for a patient so sensitive to again handle beryllium.

Estimation of beryllium in the urine may reveal its presence years after exposure since beryllium is stored in the bones and only very slowly excreted. A positive finding only demonstrates that the patient has had contact with beryllium and does not prove that it is the cause of the patient's disease.

Van Ordstrand reports that beryllium was found in $\mathrm{I}, 000$ urine specimens from healthy present and former beryllium workers. A negative finding does not exclude beryllium disease, but one isolated 24-hour specimen is not sufficient and repeated tests should be carried out. Even after repeated examinations it has not been possible to demonstrate the metal in the urine in every case. It may be possible to demonstrate beryllium in skin granulomata and it is usually present in lung tissue if a lung biopsy is carried out. It was found in four out of five lung biopsies performed by Denardi et al. (1953).

In the case in which the beryllium was not found the skin patch test proved positive, and they therefore considered the patch test has superseded lung biopsy as a diagnostic test. The 
patch test has the advantage that it shows the patient has had previous contact with beryllium and that the patient has actually become sensitized.

\section{Course and Treatment}

In contrast to sarcoidosis, the prognosis in beryllium disease is not good. Until the introduction of steroid treatment reported mortality was 35 per cent., the patients dying of progressive pulmonary fibrosis and cor pulmonale. A few patients have had spontaneous remissions, but some symptoms and radiographic changes remained and roughly 50 per cent. of patients have been left moderately or severely disabled.

Recent figures from the Progress Report of the Beryllium Case Registry are more encouraging as there have been only two deaths amongst IOI cases treated with steroids in 1954 and 1955 . It is believed that the decline in fatality rate can largely be ascribed to the steroid therapy though the decline had begun earlier and may be partly due to the recognition of more early and mild cases.

'Treatment with corticotrophin or cortisone, though not invariably successful, is the only treatment of proven benefit. Rogers (1957) has recently reviewed the published accounts of the use of steroids which are in the main favourable, and describes the improvement in the general condition of one case when given short courses of corticotrophin. My patient (Sneddon, 1955) has been treated with cortisone, at first $100 \mathrm{mg}$. daily and latterly a maintenance dose of $50 \mathrm{mg}$. daily. Her general condition has improved and the skin lesions have disappeared, but there has been no radiological improvement.

Fortunately tuberculosis does not complicate beryllium disease, and there has been as yet no report of tuberculsis in a case treated with steroids.

\section{Industrial Hazards of Beryllium}

Since one of the important criteria of diagnosis is a knowledge of exposure to beryllium, it is important to establish those industrial processes which carry the hazard. The following table (Hardy, 1956) lists the known risks:

Beryllium metallurgy.

Ceramic operations.

Radio tube manufacturing.

Atomic energy development.

Neighbourhood contamination.

Use of alloys containing more than 4 per cent. beryllium.

Extraction of beryllium.

Fluorescent powder manufacturing.

Fluorescent lamp manufacturing.

Fluorescent lamp salvage.

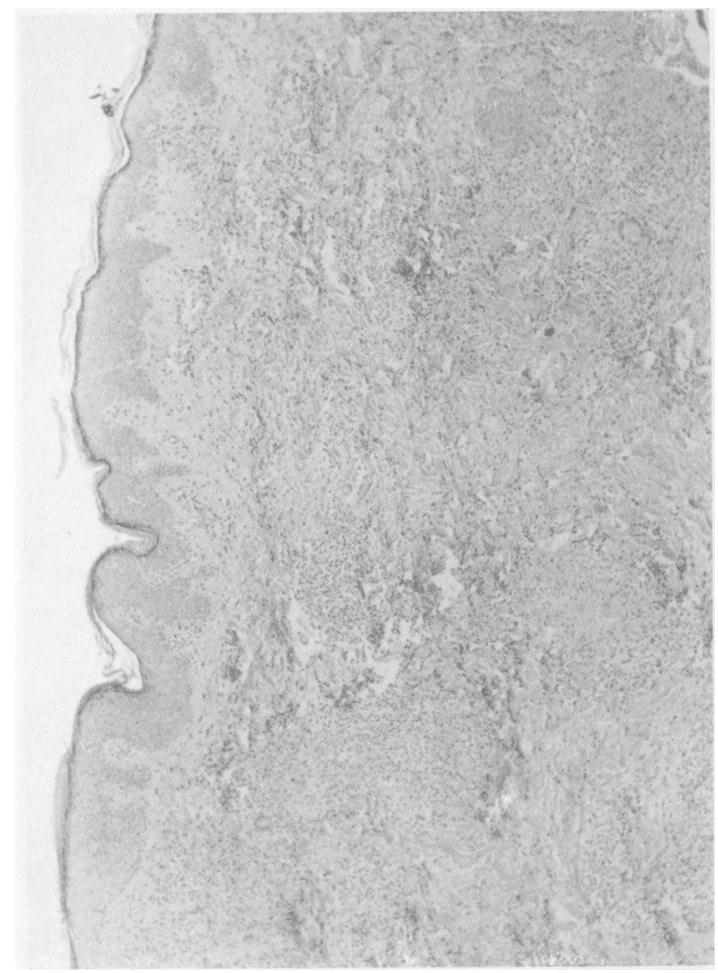

FIG. 2.- Histological changes of patch test skin showing sarcoid reaction and no epidermal change. Magnification times 40 .

Neon sign manufacturing.

Beryllium alloy manufacturing.

Accidental and unforeseen contact may occur, such as the possibility that refuse collectors and scrap dealers may come in contact with broken fluorescent tubes or copper alloys of beryllium.

It is vital that industry should be aware of the risks of beryllium so that preventive measures may be taken. It was possible to control the acute pneumonitis caused by beryllium when it became realized that there was a clear-cut relationship between the incidence of the disease and the concentration of beryllium in the air.

The prevention of chronic beryllium disease is not so simple since the amount of beryllium necessary to cause the disease may be fantastically small. Nor is the incidence amongst those exposed high; Sterner and Eisenbud (195I) quote six cases amongst 1,700 workers at risk, an incidence of only 0.3 per cent. It appears from this low incidence and the way the disease behaves that it is an allergic reaction rather than a true toxic process. This seems even more probable in view of the evidence in proven cases of skin hypersensitivity to beryllium.

Until I 955 it had been supposed that beryllium 


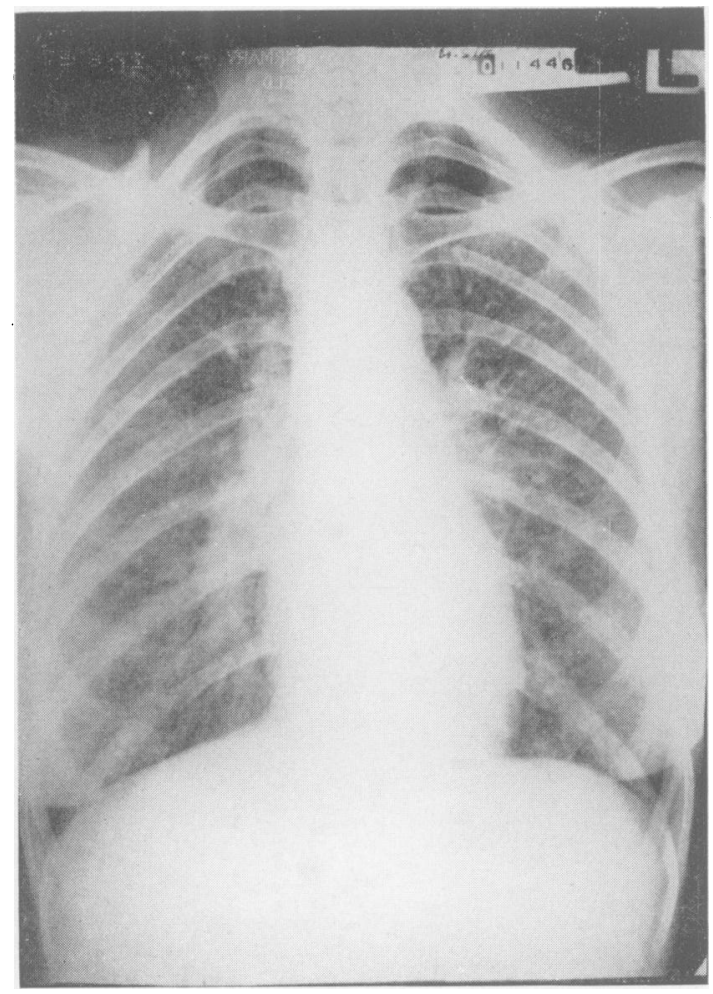

FIG. 3.-Chest radiograph of the case of beryllium disease showing miliary pin-head shadows throughout both lung fields and hilar gland enlargement.

alloys containing less than 2 per cent. beryllium were safe, but from my experience even these can give rise to beryllium disease. The following brief report of a hitherto unpublished case is included because it underlines so many features of the disease, including the mystery of how the patient contracted it.

A married woman of 38 developed several painless red papules on the backs of the hands and fingers and was referred to hospital in June 1957. The papules had appeared six months previously. At times they had become ulcerated. For the last two years she had also noticed shortness of breath on exertion but had otherwise felt well and had not lost weight.

\section{Occupational History}

From October $195^{\circ}$ to December $195^{2}$ she had been employed by the same firm of precious metal smelters where my previous case of beryllium disease had worked. Her job consisted of drying sheet metal which had been washed in plain water in a trough containing sawdust; this she brushed off with a small hand brush. Some of the sheet metal was 2 per cent. beryllium copper alloy and she occasionally scratched her hands on this. No evidence of a source of beryllium contamination of the air could be discovered in the workshop.

After leaving this work in 1952 she did only housework and thus had no contact with beryllium for five years before the first skin lesions appeared.

On examination in June 1957 the only abnormality detected was the skin eruption which consisted of linear infiltrated reddish blue papules on the backs of both hands and the sides of several fingers. There were also brownish flat papules I to $2 \mathrm{~mm}$. diameter on the flexor aspect of both wrists and some of these were arranged in linear distribution. No abnormal physical signs were found in the chest and there was no enlargement of liver, spleen or lymph glands.

\section{Investigations}

Histological examination of a papule from the right hand showed aggregation of tubercle-like follicles around a larger area of fibrinoid necrosis. No acid-fast or doubly refractile materials were seen.

Radiological examination of the chest showed miliary pinhead shadows distributed throughout both lungs. These are rather larger and coarser than those seen in our previous cases of berylliumb disease. There is also some enlargement of the hilar glands.

A tomograph confirmed enlargement of the hilar lymph nodes. No bony change was present in the hands and feet.

Mantoux I/10,000 and I/100 were negative. E.S.R. was $17 \mathrm{~mm}$. in one hour and a complete blood count was normal.

A patch test, using I per cent. beryllium sulphate, gave an intensely positive response in 48 hours and a control test with I per cent. lithium sulphate was negative. The patch test site became infiltrated and scaly and five weeks later was easily visible. A biopsy performed at that time showed an intense sarcoid granulomatous infiltration extending down to the subcutaneous fat.

This therefore is another example of beryllium disease in a woman whose only contact was with 2 per cent. beryllium copper alloy some three years before she developed symptoms. By the time skin lesions took her to her doctor quite advanced lung changes were present. The diagnosis appears definite in view of the history of contact with beryllium; the lung changes, the histology of the skin lesion and the patch tests results.

\section{Summary}

The history and main features of beryllium 
disease are described and illustrated by a hitherto unpublished case report of beryllium disease in a woman whose only contact with beryllium was handling 2 per cent. beryllium copper alloy sheets.

\section{BIBLIOGRAPHY}

AGATE, J. N. (I948), Lancet, ii, 530.

(:HESNER, (. (1950), Ann. intern. Med., 32, 1028.

CUR'TIS, G. H. (1951), Arch. Derm. Syph. (A.M.A. ), 64, 470.

DENARDI, J. M. VA.N, ORDS'TRAND, H. S., CLRTIS, (;. H., and ZIELINSKI, J. (1953), Arch. industr. Hyg., 8, I.

(;ELMAN, I. (1936), .7. industr. Hyg., 18, $37 \mathrm{I}$.

GRIER, R. S., NAISH, P., and FREIMAN, D. (;. (1948), Ibid., 30, 228.

HARDY, H. L., and TABERSHAW, I. R. (19+6), Ibid., 28, 197.

HARDY, H. L. (195I), Lancet, ii, 448 .

I IARDY, H. I. (1956), Amer. Rer. Tuberc., 74, 885.
JAMES, D. GERAINT (1956), personal communication.

JORDAN, W. (I 957), personal communication.

Lancet Annotation (195I), i, I 357.

LEDERER, H., and SAVAGE, J. (1954), Brit. F. industr. Me:l. II, 45 .

LLOYD-DAVIES T. A., and HARDING, H. E. (1950), Ibid 5,671 .

MARRADI FABRONI, S. (1935), Med. d. Lavoro, 26, 297

Progress Report of the Beryllium Case Registry for 1956, Massachusetts General Hospital, Boston I4.

ROGERS, W. N. (1957), Lancet, ii, 267.

SNEDDON, I. B. (I955), Brit. med. F., i, $144^{8}$.

STERNER, J. H., and EISENBUD, M. (1951), Industr. Hlth Monthly, II, 104 .

VAN ORDS'TRAND, H. S., HUGHES, R., and ('ARMODY. M. G. (1943), Cleveland Clin. Quart., ro, ro.

VAN ORDSTRAND, H. S. (1954), Arch. industr. Hyg., 9, 232.

WEBER, H. H., and ENGLEHARDT, W. E. (I 9.33), Z. (jew H.g., IO, 4 I .

WILSON, S. A. (1948), Radiology', 50, 770.

\section{RUTHIN CASTLE, NORTH WALES}

A Clinic for the diagnosis and treatment of Internal Diseases (except Mental or Infectious Diseases). The Clinic is provided with a staff of doctors, technicians and nurses.

The surroundings are beautiful. The climate is mild. There is central heating throughout. The annual rainfall is 30.5 inches, that is less than the average for England.

The Fees are inclusive and vary according to the room occupied.

For particulars apply to THE SECRETARY, Ruthin Castle, North Wales.

Telegrams: Castle, Ruthin

Telephone: Ruthin 66

Bibliography contimued from page 247-Professor Niels Danbolt, M.D. BIBLIOGRAPHY

BESNIER, E. (1898), Ann. Derm. Syph. (Paris), ro, 333.

BOECK, C. (1899), F. cutan. Dis., 17, 543.

BOECK, C. (1916), Arch. Derm. Syph. (Wien), 73, 7I.

BRUINS SLOT, W. J., GOEDBLOED, J., and GOSLINGS, J. (1938), Acta med. scand., 94, 74.

DANBOL'T, N. (1954), 'Sarcoidosis, in Mackenna: Modern 'Trends in Dermatology,' London.

DANLOS (1901), Ann. Derm. Syph. (Paris), 2, 576.

DARIER, J., and ROUSSY, G. (1904), Ibid., 5, 144.

HEERFORDT, C. F. (1909), Arch.f. Ophthalm., 70, 254.

IIUTCHINSON, J. ( 1898 ), 'Archives of Surgery,' Hutchinson, 9, 307 .

JUNGIIN(;, O. (1910), Fortschr. Rimtgenstr., 27, 375
KVEIM, A. (19+1), Nord. Med., 9, 196.

KUTZNITZKY, E., and BITTORF, A. (19)15), M. med. W'schr., 62, 1349 .

I.OFGRE.N, S. (1953), Acta med. scand., 145, 424.

RICKER, W., and CLARK, M. (r949), Amer. \%. Clin. Path., 19, 725

QUINQUAUD (1892), Ann. Derm. Syph. (Paris), 3, Iit2.

RIEDFR, H. (1910), Fortschr. Rüntgenstr., 15, 125.

SALVESEN, H. A. (1935), Acta med. scand., 86, 127.

SlHaumann, J. (1936), Brit. F. Derm., 48, 399.

TenNeson, M. (I892), Ann. Derm. Syph. (Paris), 3, I I 42

WILLIAMS, R. H., and NICKERSON, D. A. (1935), Proc. Sioc. exp. Biol. (N.Y.), 33, 403 .

Bibliography comtimued from page 258-Louis E. Siltzbach, M.D.

NICKERSON, D. A. (19+1), cited by Appel, B., Arch. Derm. Syph. (Chicago), 43, 172 .

NI'TTER, L. (1953), Acta radiol. (Stockh.) (Suppl.), ro5, I-202. PEPYS, J. (1955), Amer. Rev. 'Tuberc., 71, 49.

PUTKONEN, T. (1943), Acta derm.-7enereol. (Stockh.) (Suppl.), 23, $1-194$.

QUINN, E. L., BUNCH, D. C., and YA(iEL, E. M. (1955), Y. invest. Derm., 24, 595.

REFVEM, O. (1954), Acta med. scand. (Suppl.), 294, I-1 46 .

REID, J. D. (1956), N.Z. med. F., 55, 275.

ROGERS, F. J., and HASERICK, J. R. (1954), F. invest. Derm., 23, 389 .

ROSTENBERG, A., SZYMANSKI, F. J., BREBIS, G. J., HAEBERLIN, J. B., and SENEAR, F. E., (1953), Arch. Derm. Syph. (Berl.), 67, 306.
SANDS, J. H., PAL.MER, P. P., MAYOCK, R. I., and ('REGER, W. P. (1955), Amer. Ұ. Med., 19, 401 SCADDING, J. (j. (1956), Tubercle, 37, 371 .

SCHIER, W. W., ROTH, A., OSTROFF, G., and SCHRIFT, M. H. (1956), Amer. F. Med., 20, 94.

SEEBERG, G. (1951), Acta derm.-venereol. (Stockh.), 3 I, 426. SILTZBACH, L. E., and EHRLICH, J. C. (1954), Amer. F. Med.
16, 790 .

SILTZBACH, I. E. (1957), Ibid., 22, 84I.

SONES, M., and ISRAEL, H. L. (1954), Ann. intern. Med., 40, 260 SONES, M., ISRAEI, H. I., KRAIN, R., and BEERMAN, H. (1955), $\mathcal{F}$. invest. Derm., 24, 353.

TEILUM, G. (1948), Amer. F. Path., 24, 389.

ZETTERGREN, L. (1954), Acta Śoc. Med. upsalien. (Suppl.), 